\title{
Giant lipomas of the upper extremity
}

\author{
Brian Allen $\mathrm{MD}^{1,2}$, Christine Rader $\mathrm{MD}^{1,2}$, Alan Babigian $\mathrm{MD}^{1}$
}

\begin{abstract}
B Allen, C Rader, A Babigian. Giant lipomas of the upper extremity. Can J Plast Surg 2007;15(3):141-144.

Lipomas are slow-growing soft tissue tumours that rarely reach a size larger than $2 \mathrm{~cm}$. Lesions larger than $5 \mathrm{~cm}$, so-called giant lipomas, can occur anywhere in the body but are seldom found in the upper extremities. The authors present their experiences with eight patients having giant lipomas of the upper extremity. In addition, a review of the literature, and a discussion of the appropriate evaluation and management are included.
\end{abstract}

\section{Des lipomes géants des membres supérieurs}

Les lipomes sont des tumeurs des tissus mous à croissance lente qui atteignent rarement plus de deux centimètres. Des lésions de plus de cinq centimètres, qu'on appelle lipomes géants, peuvent se former n'importe où sur le corps, mais on les observe rarement sur les membres supérieurs. Les auteurs présentent leur expérience auprès de huit patients ayant un lipome géant d'un membre supérieur. L'article inclut une analyse bibliographique et un exposé de l'évaluation et de la prise en charge pertinentes.

\section{Key Words: Giant lipoma; Liposarcoma; Upper extremity}

\begin{abstract}
T ipomas are the most common mesenchymal tumour. They are Lelieved to arise from primordial adipocytes, not from adult fat cells, therefore increasing in size as a patient accumulates adipose tissue but not decreasing with weight loss. They usually develop as well-circumscribed, encapsulated masses that have a doughy feel and are freely mobile beneath the skin. Lipomas can occur in many locations, but occur most commonly in the subcutaneous tissue of the head, neck, shoulders and back. They can also be found intermuscularly, intramuscularly, interosseously, associated with viscera or at a site of prior trauma. Subtypes include conventional lipomas, fibrolipomas, angiolipomas, spindle cell lipomas, myelolipomas and pleomorphic lipomas. Their slow, usually painless growth can lead to a large size at presentation, especially when located in deep subfascial planes.

Cosmetic deformity or compressive symptoms usually bring lipomatous masses of the upper extremity to medical attention earlier than rapidly growing masses in other locations of the body. Previous studies have defined a giant lipoma of the upper extremity as larger than $5 \mathrm{~cm}$ in any one dimension; a tumour of this size warrants a work-up for malignancy (1). Giant lipomas of the upper extremity are rare, but when they occur, an appropriate workup must be done. This should be followed by adequate open surgical excision and repeat examination over time to monitor for recurrence.
\end{abstract}

\section{CASE PRESENTATIONS}

A series of eight consecutive patients, four male and four female, who were evaluated at Hartford Hospital, Connecticut, USA from 2003 to 2007 with giant lipomatous masses of the upper extremity is presented. The patients ranged in age from 15 to 70 years with a mean age of 53 years (Table 1 ). The tumours ranged from $14 \mathrm{~cm} \times 12 \mathrm{~cm} \times 2 \mathrm{~cm}$ to $5 \mathrm{~cm} \times 4 \mathrm{~cm} \times 2 \mathrm{~cm}$ in size. Each patient underwent excision of the mass with primary closure. Specimens were sent to pathology postoperatively. Seven of the eight patients had benign lipomas; patient 5 had a well-differentiated liposarcoma. Four cases are presented here in more detail.

\section{Patient 2}

A 63-year-old man presented with a mass on his right forearm. The patient reported having a 'fatty tumour' removed from the same location two years earlier in Puerto Rico. He had noticed recurrence of the mass approximately one year after the initial surgery, and magnetic resonance imaging (MRI) had revealed a mass between the brachioradialis and supinator muscles of the right arm, suspicious for lipoma. He had elected to observe the mass at that time but at presentation reported the lesion to be larger than ever, and complained of new-onset pain and tenderness in his right forearm with motion in his elbow. Physical examination revealed a scar from the previous excision on the volar aspect of his forearm. A mildly tender mass was palpated just below the scar. Sensation and motor function were intact throughout his right hand and forearm.

A repeat MRI two years after the initial excision demonstrated a mass with homogeneous fat signal volar to the brachioradialis, and posterior and radial to the pronator teres muscle. At this time, the patient underwent a radical excision of a $4 \mathrm{~cm} \times 3 \mathrm{~cm} \times 2 \mathrm{~cm}$ mass with primary closure. Final pathology revealed a lipoma.

The patient later returned, complaining of recurrance of the mass. Physical examination revealed a $3.5 \mathrm{~cm} \times 3.2 \mathrm{~cm}$ mildly tender, well-circumscribed subcutaneous mass just proximal to the most recent incision. When palpated, the patient reported numbness and tingling in the ulnar distribution of his fingers. A repeat MRI did not demonstrate recurrence of the fatty lesion; however, a re-exision was performed primarily for

${ }^{1}$ Hartford Hospital, Hartford; ${ }^{2}$ University of Connecticut, Farmington, Connecticut, USA

Correspondence: Dr Brian Allen, 85 Seymour Street, Hartford, Connecticut 06106, USA. Telephone 860-548-7338, fax 860-524-2654, e-mail BrAllen@resident.uchc.edu 
TABLE 1

\section{Case series}

\begin{tabular}{|c|c|c|c|c|c|c|c|}
\hline Patient & Age & Sex & Location & Surgery & Size & Pathology & Recurrence \\
\hline 1 & 48 & Male & Right anterior shoulder & Excision with primary closure & $5 \mathrm{~cm} \times 4 \mathrm{~cm} \times 2 \mathrm{~cm}$ & Lipoma & No \\
\hline \multirow[t]{2}{*}{2} & 63 & Male & Right forearm & Excision with primary closure & $4 \mathrm{~cm} \times 3 \mathrm{~cm} \times 2 \mathrm{~cm}$ & Lipoma & Yes \\
\hline & & & & & $4 \mathrm{~cm} \times 3 \mathrm{~cm} \times 1 \mathrm{~cm}$ & & \\
\hline 3 & 53 & Female & Left shoulder & Excision with primary closure & $6 \mathrm{~cm} \times 5 \mathrm{~cm} \times 2 \mathrm{~cm}$ & Lipoma & No \\
\hline 4 & 15 & Female & Left forearm & Excision with primary closure & $14 \mathrm{~cm} \times 12 \mathrm{~cm} \times 2 \mathrm{~cm}$ & Lipoma & No \\
\hline 5 & 53 & Female & Right forearm & Excision with primary closure & $12 \mathrm{~cm} \times 6 \mathrm{~cm} \times 2 \mathrm{~cm}$ & Well-differentiated liposarcoma & No \\
\hline 8 & 61 & Female & Right elbow & Excision with primary closure & $7 \mathrm{~cm} \times 3 \mathrm{~cm} \times 3 \mathrm{~cm}$ & Lipoma & No \\
\hline
\end{tabular}
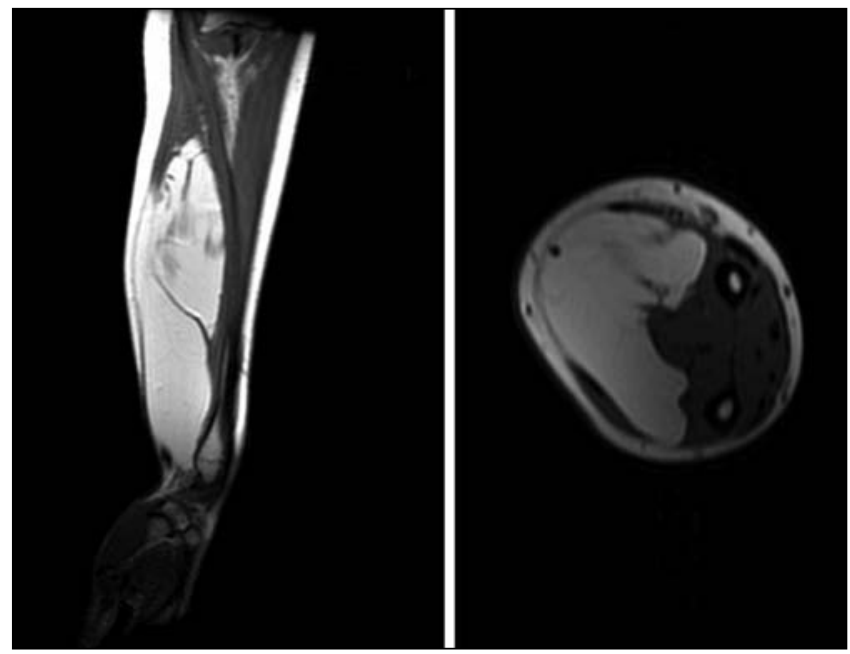

Figure 1) Patient 4. Preoperative magnetic resonance imaging showing a large fatty mass volar to the flexor muscles of the left hand

symptomatic relief. Radical excision of a $4 \mathrm{~cm} \times 3 \mathrm{~cm} \times 1 \mathrm{~cm}$ mass with primary closure was achieved. Final pathology revealed a recurrence of his lipoma.

\section{Patient 4}

A 15-year-old girl presented with a mass on her left forearm. She had first noticed the lesion four years earlier and reported that it had been steadily enlarging over the previous two months. On examination, there was a spongy, ill-defined mass covering nearly the entire volar aspect of her left forearm. There were no overlying skin changes, and her left arm had intact neurovasculature.

MRI revealed a large, well-circumscribed, homogeneous fatty mass. The lesion was located intramuscularly, within and volar to the extrinsic flexor muscles of the left hand (Figure 1). There was no postgadolinium enhancement of the lesion. A radical excision and primary closure were performed (Figure 2). The mass was sent to pathology intraoperatively and revealed a $14 \mathrm{~cm} \times 12 \mathrm{~cm} \times 2 \mathrm{~cm}$ lipoma. Postoperatively, the patient recovered well with no functional deficits.

\section{Patient 5}

A 53-year-old woman presented, complaining of recent spontaneous rapid growth of a mass in her right forearm. This lesion had been previously biopsied by a surgical oncologist, revealing a lipoma with myxoid change. On physical examination, she had an obvious mass on her right forearm. The lesion was well
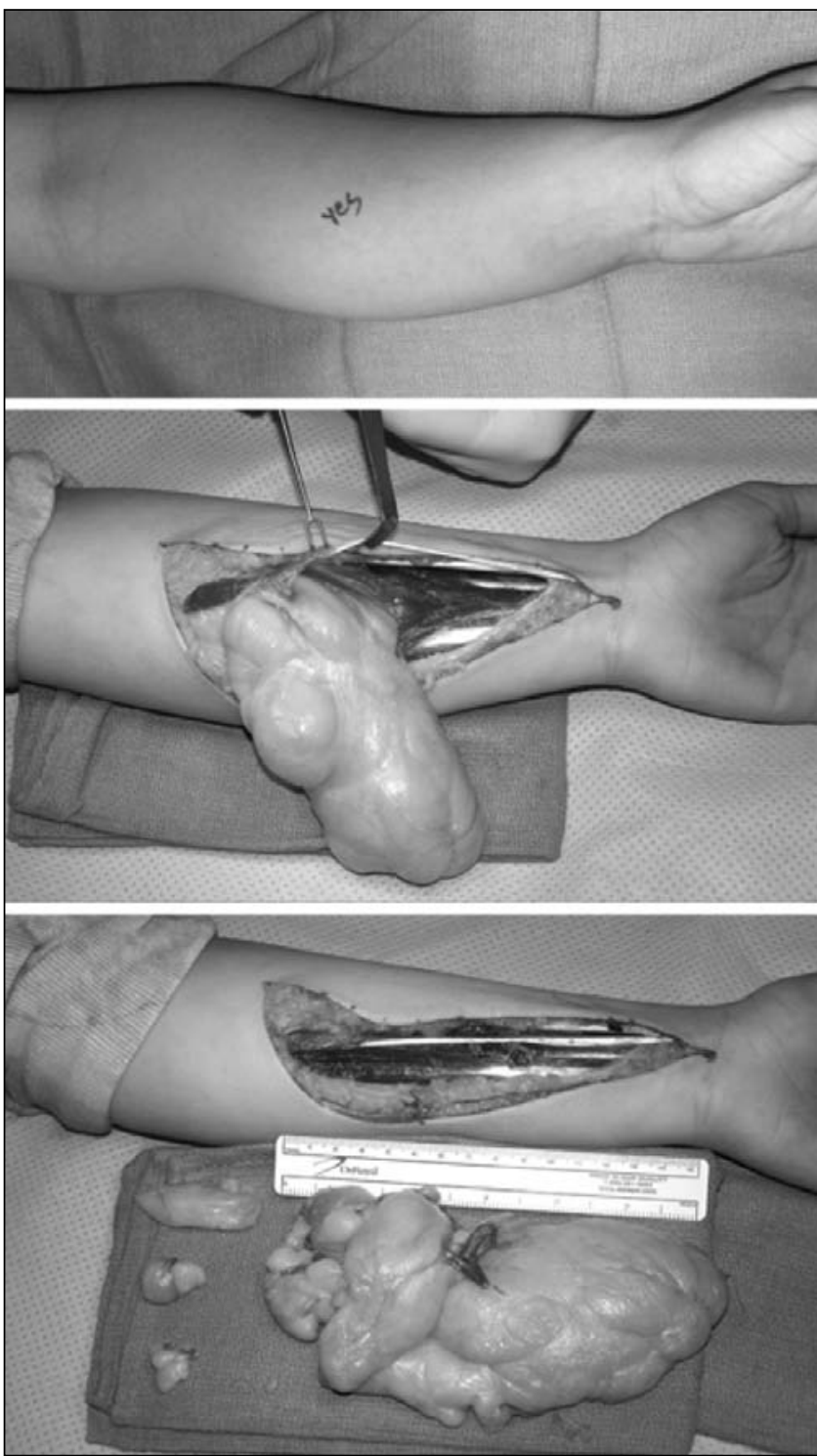

Figure 2) Patient 4. Intraoperative images of the excision. Final pathology revealed a $14 \mathrm{~cm} \times 12 \mathrm{~cm} \times 2 \mathrm{~cm}$ lipoma

circumscribed and appeared somewhat fixed to deeper tissues. Her forearm and hand had intact neurovasculature, with no compromise in motor function due to the mass. 

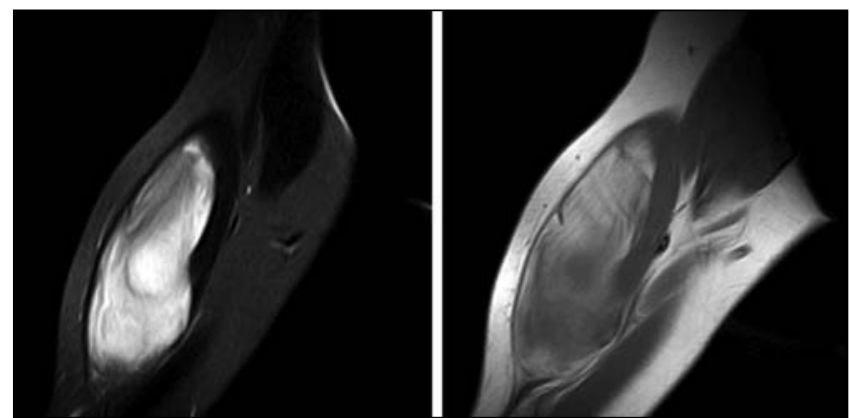

Figure 3) Patient 5. Preoperative T1- and T2-weighted magnetic resonance image showing a mass within the right brachioradialis muscle

MRI revealed a mass within the brachioradialis muscle of the right arm. The mixed fatty and soft tissue density of the mass, along with the postgadolinium enhancement and deep location, was suspicious for liposarcoma (Figure 3). The patient underwent radical excision of a $12 \mathrm{~cm} \times 6 \mathrm{~cm} \times 2 \mathrm{~cm}$ well-encapsulated mass that was adherent to the muscle on the dorsal aspect of the lesion (Figure 4). Primary closure was achieved. Final pathology revealed a well-differentiated liposarcoma. The patient healed well with no complications.

\section{Patient 7}

A 61-year-old man being followed for a foot wound reported the growth of a mass in his left triceps over the previous several weeks. The mass was nontender, and he recalled no antecedent trauma. On physical examination, a deep, well-circumscribed mass was palpated in the region of the left triceps. The mass was freely movable, with no overlying skin changes.

MRI revealed a mass within the left triceps consistent with a low-grade lipomatous lesion, likely an intramuscular lipoma (Figure 5). Of note, there was mild fatty atrophy seen within the biceps muscle, likely related to remote injury. The patient underwent radical excision of the lesion, which was found to be $10 \mathrm{~cm} \times 6 \mathrm{~cm} \times 3 \mathrm{~cm}$ in size (Figure 6). Final pathology revealed lipoma.

\section{DISCUSSION}

Most lipomas are benign and can occur alone or in multiple locations. There is a report (2) of an individual having as many as 160 individual lesions. Lipomas can arise spontaneously or as part of a syndrome such as hereditary multiple lipomatosis, adiposis dolorosa, Gardner's syndrome and Madelung's disease (3). Lipomas occur more frequently in female patients, presumably due to their tendency to accumulate more adipose tissue; however, we did not observe this trend in our series.

Lipomas usually grow at a very slow rate, and the etiology of rapid growth into giant lipomas is still a matter of debate. It has been suggested that blunt trauma can cause rupture of the fibrous septa and anchorage connections between the skin and deep fascia, allowing the adipose tissue to proliferate (4). Although the patient 7 denied any trauma to the area, there was evidence of remote injury to the left upper extremity on MRI. This may have led to the eventual rapid growth of an already existing intramuscular lipoma.

No matter the mechanism of rapid growth, the main concern when evaluating a giant lipoma in the upper extremity is to rule out malignancy. Liposarcomas are the most common soft tissue sarcomas, comprising $7 \%$ to $27 \%$ of all soft tissue sarcomas (5).
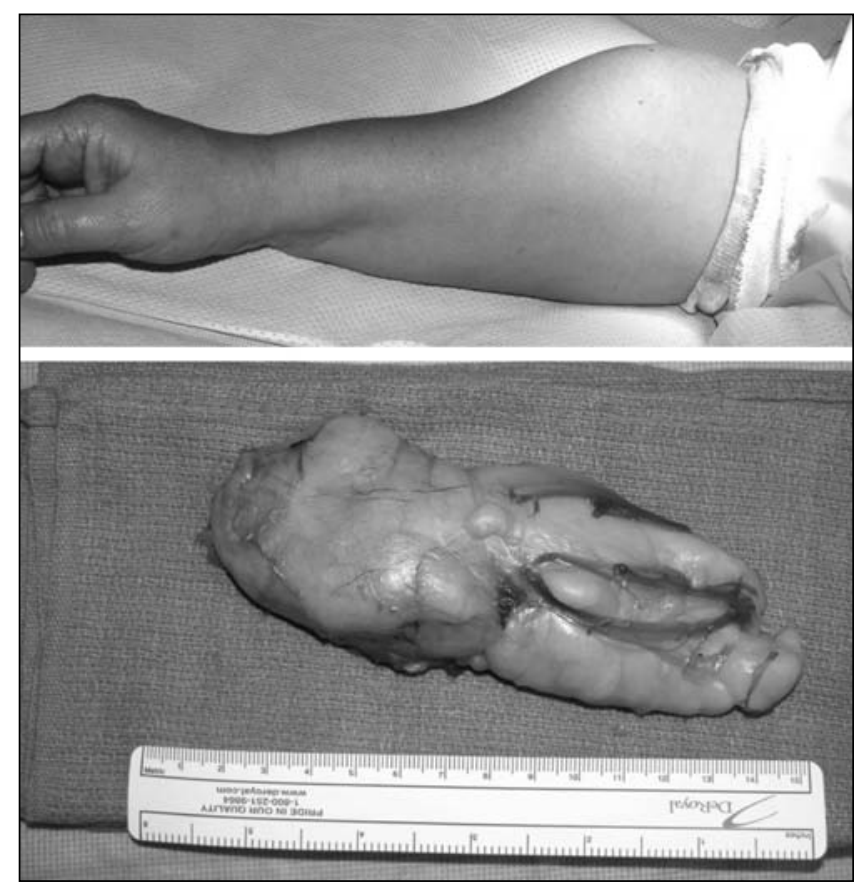

Figure 4) Patient 5. Intraoperative images of the excision. Final pathology revealed a $12 \mathrm{~cm} \times 6 \mathrm{~cm} \times 2 \mathrm{~cm}$ well-differentiated liposarcoma
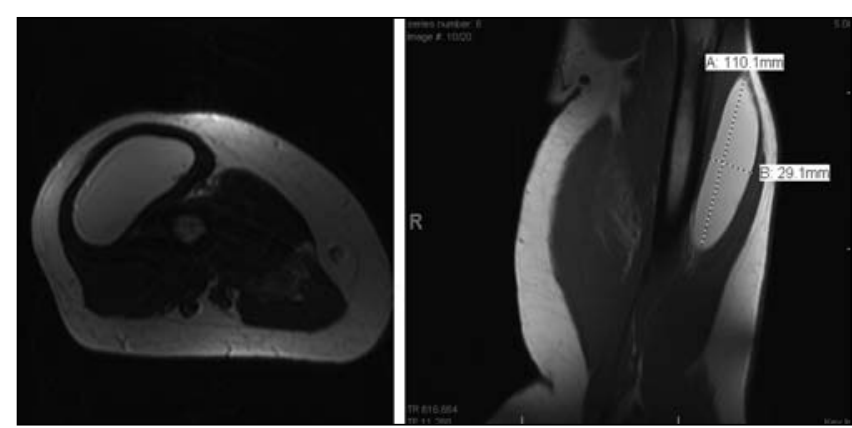

Figure 5) Patient 7. Preoperative magnetic resonance image showing an $11 \mathrm{~cm} \times 2.9 \mathrm{~cm}$ oval-shaped mass located intramuscularly in the left triceps

They typically arise in the fourth to sixth decade of life. Liposarcomas consist of lipoblasts and may occur wherever fat is present, but are most commonly found within intramuscular fatty tissue. Histological subtypes of liposarcomas include welldifferentiated, myxoid, round cell and pleomorphic liposarcomas. Well-differentiated liposarcomas exhibit low malignant potential, myxoid liposarcomas display intermediate malignant behaviour, and round cell and pleomorphic liposarcomas exhibit aggressive behaviour with early metastasis. Well-differentiated liposarcomas, as seen in patient 5 , account for approximately $40 \%$ to $45 \%$ of liposarcomas (1). Recent rapid growth, size larger than $5 \mathrm{~cm}$ and intramuscular location have all been reported to be risk factors for malignancy $(1,5,6)$.

Proper evaluation of a large mass in the upper extremity must include imaging or tissue sampling to rule out malignancy. MRI or biopsy are the two best options available. The possibility of an incompletely representative biopsy leading to misdiagnosis has led some to recommend MRI before attempting biopsy. On MRI, a lipoma appears as a mass with homogenous fat signal intensity surrounded by a pseudocapsule. Gadolinium-enhanced MRI has been reported to allow easy 

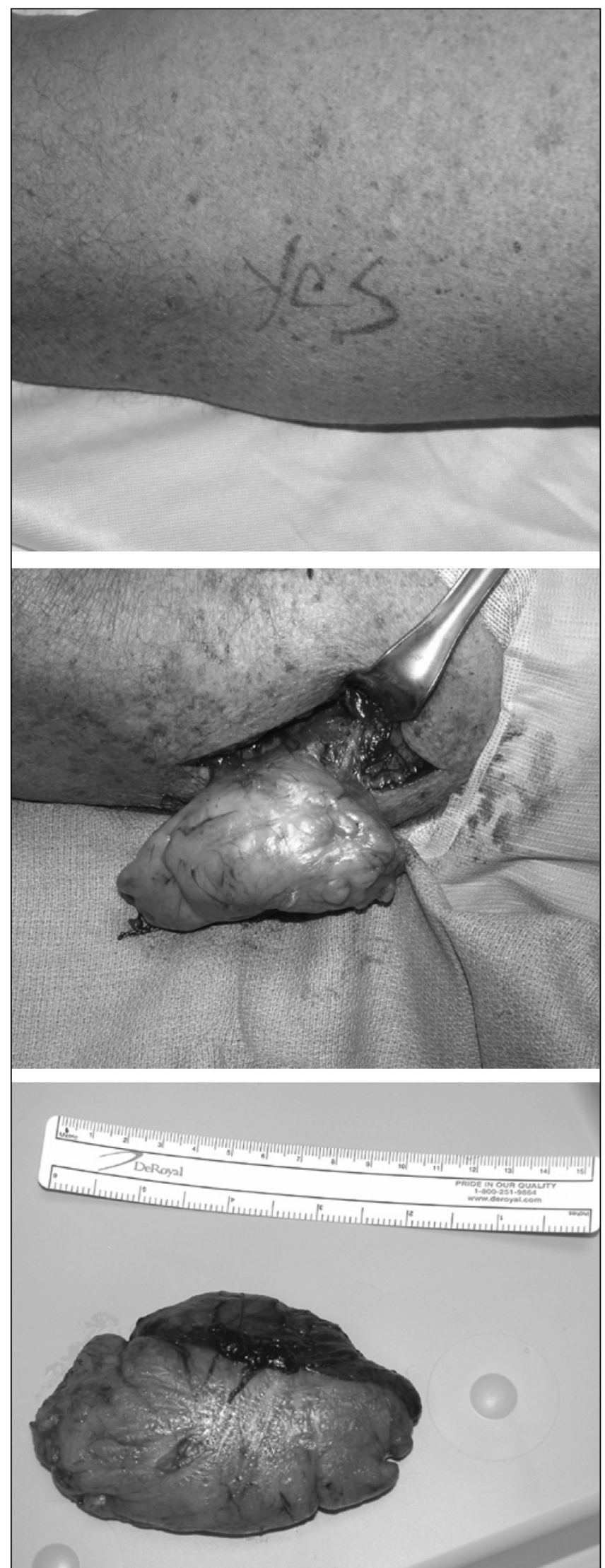

Figure 6) Patient 7. Intraoperative images of the excision. Final pathology revealed a $10 \mathrm{~cm} \times 6 \mathrm{~cm} \times 3 \mathrm{~cm}$ lipoma distinction of lipomas from well-differentiated liposarcomas due to increased levels of vascularity seen in septal structures within the lesion (7). High-grade liposarcomas have little fat on imaging, and dedifferentiated liposarcomas show obvious changes from a low-grade to high-grade tumour within the lesion (8). Ultrasound- or computed tomography-guided biopsy can then be used to target areas of radiological concern. Ultimately, surgical excision should be performed, possibly followed by radiation and chemotherapy. If a lipoma is incompletely excised, it may recur, as was seen in patient 2 , who had had a lipoma removed from the same location two years previously. Liposarcomas are notorious for local recurrence, and even with attempted total resection, local recurrence rates may be as high as $50 \%(1)$.

Suction-assisted lipectomy has been suggested as a treatment option for giant lipomas, but the need for complete removal to prevent recurrence, along with the inability to predict where nerves and other vital structures have been displaced, renders this mode of treatment less attractive.

The proper management of giant lipomas is open excision. Lipomas are usually well encapsulated, allowing relatively straightforward complete removal. Intramuscular location makes removal more technically challenging and may require removal of some surrounding muscle to ensure adequate margins. Finally, a full pathology report on the specimen is required to determine the possible need for further treatment.

\section{CONCLUSIONS}

All lipomas in the upper extremities measuring larger than $5 \mathrm{~cm}$ in a single dimension should be surgically removed due to malignant potential. Preoperatively, imaging is important to delineate the extent of the lesion and to assist in operative planning. We recommend MRI for its ability to discern tissue planes. Surgical removal of lipomas may require significant dissection and mobilization of neurovascular structures for successful resection, and preoperative discussions with patients regarding potential loss of function are essential. Any lipomatous mass may recur with incomplete excision, and liposarcomas may require a larger repeat excision, chemotherapy or radiation.

\section{REFERENCES}

1. Cribb GL, Cool WP, Ford DJ, Mangham DC. Giant lipomatous tumours of the hand and forearm. J Hand Surg [Br] 2005;30:509-12.

2. Phalen GS, Kendrick JI, Rodriguez JM. Lipomas of the upper extremity. A series of fifteen tumors in the hand and wrist and six tumors causing nerve compression. Am J Surg 1971;121:298-306.

3. Salam GA. Lipoma excision. Am Fam Physician 2002;65:901-4.

4. Terzioglu A, Tuncali D, Yuksel A, Bingul F, Aslan G. Giant lipomas: A series of 12 consecutive cases and a giant liposarcoma of the thigh. Dermatol Surg 2004;30:463-7.

5. Celik C, Karakousis CP, Moore R, Holyoke ED. Liposarcomas: Prognosis and management. J Surg Oncol 1980;14:245-9.

6. Silistreli OK, Durmus EU, Ulusal BG, Oztan Y, Gorgu M. What should be the treatment modality in giant cutaneous lipomas? Review of the literature and report of 4 cases. Br J Plast Surg 2005;58:394-8

7. Yang YJ, Damron TA, Cohen H, Hojnowski L. Distinction of welldifferentiated liposarcoma from lipoma in two patients with multiple well-differentiated fatty masses. Skeletal Radiol 2001;30:584-9.

8. Ilaslan H, Sundaram M. Advances in musculoskeletal tumor imaging. Orthop Clin North Am 2006;37:375-91. 